\title{
Associativismo no setor turístico como vetor do comportamento de coopetição
}

Associationism in the tourism sector as a vector of coopetition behavior Asociacionismo en el sector turístico como vector del comportamiento de coopetición

http://dx.doi.org/10.18472/cvt.18n2.2018.xxx

Adriana Fumi Chim-Miki 〈adriana.chimmiki@gmail.com > Universidade Federal de Campina Grande (UFCG), Campina Grande, PB, Brasil

Rosa Maria Batista-Canino 〈rosa.batistacanino@ulpgc.es >

Universidad de Las Palmas de Gran Canaria (ULPGC), Las Palmas de Gran Canaria, Espanha

Pino Medina-Brito 〈pino.medinabrito@ulpgc.es >

Universidad de Las Palmas de Gran Canaria (ULPGC), Las Palmas de Gran Canaria, Espanha

CRONOLOGIA DO PROCESSO EDITORIAL

Recebimento do artigo: 04-jun-2016

Aceite: 03-mar-2018

FORMATO PARA CITAÇÃO DESTE ARTIGO

CHIM-MIKI, A. F.; BATISTA-CANINO, R. M.; MEDINA-BRITO, P. Associativismo no Setor Turístico como Vetor do Comportamento de Coopetição. Caderno Virtual de Turismo. Rio de Janeiro, v. 18, n. 2, p. 46-62, ago. 2018.

REALIZAÇÃO

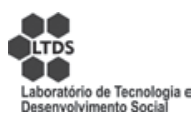

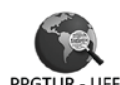

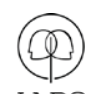

IABS
APOIO INSTITUCIONAL

COPPE

UFR]

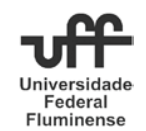

EDIÇÃO

PATROCÍNIO

IPITORA 


\section{RESUMO}

A coopetição é a intrusão da competição nas redes de cooperação, por isso é mais visível entre concorrentes diretos, no entanto, esse comportamento é intrínseco das redes interorganizacionais. Este trabalho analisa o associativismo no turismo e seu contexto crítico que propicia o comportamento de coopetição. A análise está baseada em dados quantitativos, porém, mantém o caráter qualitativo da metodologia de estudo de caso. Os dados foram extraídos de 545 questionários de percepção a empresários e entrevistas a 50 associações turísticas nas cidades de Foz do Iguaçu e Curitiba. Os resultados demonstram que o contexto associativo de Foz do Iguaçu forma redes de coopetição horizontal com mais frequência do que a cidade de Curitiba, na qual se acentua as redes verticais de coopetição. Além disso, em Foz do Iguaçu existe uma maior percepção empresarial das vantagens derivadas da associação, assim como existe maior consciência sobre o nível de interdependência e metas em comuns. As considerações finais indicam que as associações empresariais são vetores do comportamento de coopetição.

Palavras-chave: Coopetição. Associativismo. Destinos turísticos. Foz do Iguaçu. Curitiba.

\section{ABSTRACT}

The coopetition is the intrusion of competition in cooperation networks, so it is more visible among direct competitors. However, this behavior is intrinsic to institutional networks. This study examines the tourism associationism and its critical context that favors the coopetition behavior. The analysis is based on quantitative data but keeps the qualitative methodology of a case study. Two Brazilian cities are analyzed - Curitiba and Foz do Iguaçu - according to 545 perception questionnaires to entrepreneurs and 50 interviews to tourism associations. The results indicate that the associative context of Foz do Iguaçu generates horizontal coopetition networks more often than the Curitiba city, in which is accentuated the vertical networks of coopetition. Furthermore, entrepreneurial perception about benefits from Partnering and awareness of advantages from coopetition in Foz do Iguaçu is greater than Curitiba. In the same way, among the entrepreneurs, there is the higher perception of the interdependence, and shared goals in Foz do Iguaçu than in Curitiba. The final considerations indicate that business associations are vectors of coopetition behavior.

Keywords: Coopetition. Associationism. Tourism Destinations. Foz do Iguaçu. Curitiba

\section{RESUMEN}

La coopetición es la intrusión de la competencia en redes de cooperación, por lo que, es más visible entre competidores directos. No obstante, este comportamiento es intrínseco de las redes institucionales. Este trabajo analiza el asociacionismo en el turismo y su contexto crítico que propicia el comportamiento de coopetición interorganizativa. El análisis está basado en datos cuantitativos, pero mantiene el carácter cualitativo de la metodología de estudio de caso. Se analiza dos ciudades brasileñas, Curitiba y Foz do Iguacu, con base en 545 encuestas de percepción a empresarios y 50 entrevistas a asociaciones turísticas. Los resultados indican que o contexto asociativo de Foz do Iguacu forma redes de coopetición horizontal con más frecuencia de que en la ciudad de Curitiba, en la cual se acentúa las redes verticales de coopetición. Además, la percepción empresarial en Foz do Iguacu es mayor en cuanto a las ventajas derivadas de la asociación, así como existe mayor percepción de la interdependencia y de las metas compartidas. Las consideraciones finales indican que las asociaciones empresariales son vectores del comportamiento de coopetición.

Palavras clave: Coopetición. Asociacionismo. Destino Turístico. Foz do Iguaçu. Curitiba. 


\section{INTRODUÇÃO}

A cooperação empresarial e a concorrência ou competição têm sido estudadas a partir de várias perspectivas. Na literatura de cooperação interorganizacional encontra-se diversos nomes para as alianças entre organizações, um comportamento que se converteu em uma estratégia contemporânea utilizada para buscar melhores condições de trabalho, de rendimento e de competitividade para as empresas (CHENG et al., 2000).

Na maioria dos casos a cooperação empresarial é motivada por uma busca de vantagens competitivas (LUO, 2007). Assim, um construto que vem sendo considerado explicativo desse comportamento é a "coopetição", a qual representa um híbrido entre a cooperação e a competição, gerando um equilíbrio que favorece a obtenção de vantagens coletivas e individuais (PADULA; DAGNINO, 2007).

Também se observa como prática comum nos mercados atuais, a existência de organizações empresariais que reúnem as empresas em associações, gerando um fenômeno de associacionismo. Essas instituições podem ser dedicadas a empresas de uma única atividade, formando redes horizontais, como, por exemplo, associações de agências de viagens, ou associações que mesclam várias atividades empresariais, formando redes verticais e mistas. A literatura tem tratado esse fenômeno como Partnership (MOHR; SPEKMAN, 1994) ou Partnering (HARBACK et al., 1994; CHENG et al., 2000).

No turismo, a formação de associações interorganizacionais tem sido constante, e em muitas cidades elas atuam como propulsores do desenvolvimento, assumindo especialmente atividades de planejamento e comarketing do destino turístico e região (WANG; KRAKOVER, 2008), de representação e articulação política (LUO, 2007), de propulsores do conhecimento, da gestão de recursos compartilhados, da cocriação de valor (DELLA CORTE; ARIA, 2014), entre outros. Dessa forma, essas associações atuam como formadores de redes interorganizacionais, do associacionismo, onde o comportamento de coopetição é a base central do desenvolvimento de um trabalho conjunto em prol de uma meta comum apesar dos interesses individuais dos participantes (CHIM-MIKI, 2016).

Considerando essa configuração de mercado, neste artigo verifica-se o associacionismo turístico nas cidades de Curitiba e Foz do Iguaçu. Analisa-se o nível de confiança e apoio da rede empresarial turística em relação à formação do associacionismo como uma rede de coopetição tanto para o desenvolvimento do destino turístico como das próprias empresas. Assim, este artigo está dividido nas seguintes seções: primeiro, realiza uma introdução ao tema, seguido de uma fundamentação teórica sobre coopetição e Partnering (associacionismo). Uma segunda parte apresenta a metodologia de obtenção de dados e as variáveis e análises utilizadas para identificar o comportamento empresarial relacionado ao associacionismo. Finalmente, apresentam-se os resultados obtidos, discutindo-os para, em seguida, realizar as considerações finais sobre essa temática.

\section{Partnering e coopetição em turismo: convergências e divergências}

O fator associação é um ponto-chave no meio empresarial e representa a formação de alianças colaborativas entre os participantes de uma cadeia de valor. Crowley e Karim (1995) definiram "Partnering" como uma estratégia cooperativa que uma organização implanta, modificando e complementando o tradicional limite que separa as organizações em um ambiente competitivo. Dessa maneira, o Partnering pode ser utilizado para criar um ambiente coeso em que os membros associados interatuam na realização de um projeto único. 
Por outra parte, em termos básicos, a coopetição é o comportamento de cooperação e competição simultâneos (LUO, 2005). Esse comportamento pode ocorrer em nível de intraorganização, interorganizações ou inter-redes. Um destino turístico é uma entidade mista, integrada por vários componentes que podem trabalhar uns com ou contra outros (FYALL et al., 2012), e assim, a colaboração tem sido indicada como uma resposta natural e como uma das poucas estratégias que podem ser utilizadas para seu desenvolvimento integral, especialmente considerando a integração entre os stakeholders (WANG, 2008). Como resultado, tem-se observado o crescimento das redes de colaboração entre organizações (CNOs - Collaborative Network Organizations) e das organizações de gestão e marketing de destinos, como as DMOs - Destination Marketing Organization.

Essas organizações, que muitas vezes são associações empresariais existentes nos destinos turísticos, atuam como facilitadoras da relação entre os atores, sendo hubs de coopetição. Bengtsson e Kock (2000) indicam que o uso de um ator intermediário, como uma associação coletiva, minimiza as tensões intrínsecas típicas da competição, e que contribui para a formação de sistemas de coopetição mais efetivos e estáveis, pois estabelece regras e controla as ações coletivas.

A literatura sobre coopetição também apresenta tipologias desse construto, segundo diferentes perspectivas de análise, na qual, uma delas é baseada no tipo de relações que ocorre no interior da rede, classificando-as em:

1. Coopetição horizontal ou baseada em concorrência: relação entre duas ou mais empresas da mesma atividade, sendo competidores diretos em busca de benefícios individuais, normalmente muito relacionados à quota de mercado.

2. Coopetição vertical ou baseada em cooperação: relação entre duas ou mais empresas complementárias, formando alianças estratégicas por meio das quais buscam melhorar o mercado, no entanto, disputam entre elas por benefícios gerais.

3. Coopetição integral que ocorre entre toda uma rede interorganizacional ou todo um setor, incluindo empresas concorrentes, complementários, fornecedores e clientes. Nesse caso, geralmente são amplas redes associativas que focalizam o desenvolvimento setorial, ainda que cada participante busque alguma vantagem individual, que é o motivo da competição entre eles.

Traçando uma analogia entre essas tipologias de coopetição e a formação de associações empresariais, observam-se similaridades. As associações de grupos ou atividades específicas, como, por exemplo, uma associação de bares e restaurantes ou de agências de viagens, correspondem à tipologia de coopetição horizontal. Enquanto que uma associação que é formada por um Convention Bureau, por exemplo, representa uma rede de coopetição vertical. Por último, a coopetição integral pode ser vista nos casos em que se forma uma instituição de gestão integral do destino ou um organismo de governança.

Conceitualmente, alguns autores, como Brandenburger e Nalebuff (1996), consideram a coopetição no sentido amplo como integral, incluindo todos os stakeholders. Por outro lado, outra corrente teórica, como, por exemplo é defendida por Bengtsson e Kock (2000), consideram a coopetição de forma mais estreita, sendo competidores somente os que produzem e comercializam produtos similares. Porém, aplicando a destinos turísticos, a abordagem deve ser menos fechada, pois todas as empresas do destino competem entre si pelo orçamento do cliente, que é único. Assim, em certo sentido, todas as empresas são concorrentes entre si, mesmo quando seus produtos são complementares na formação da oferta turística integral. 
Garraffo (2002) considera que o nível de coopetição está baseado no nível de compromisso das empresas com a criação de mercados e com a evolução tecnológica. Situação que no turismo se relaciona com o compromisso das empresas em desenvolver o destino de forma integral ou de manter sua competitividade por meio de planejamento e inovação. Uma questão destacada nos estudos de coopetição em diversas áreas econômicas é o grau de interdependência entre os participantes. Padula e Dagnino (2007) salientam que a interdependência é tanto fonte de criação de valor econômico como um lugar para a divisão do valor gerado. Deve ser observado que, apesar da interdependência ser à base de um jogo de soma positiva, ou seja, que traz benefícios para todos, nem sempre esses benefícios serão igualitários por força das pressões competitivas.

Todo esse cenário estudado possui grande aproximação com o destino turístico e suas redes organizativas, indicando que o setor do turismo é um contexto muito adequado para o comportamento de coopetição, sendo uma teoria explicativa das relações entre os stakeholders do destino turístico (CHIMMIKI; BATISTA-CANINO, 2016). O destino turístico possui alta complementariedade e interdependência entre as empresas, elevada atomização da oferta e é comum a existência de mecanismo de gestão integrada (DELLA CORTE; SCIARELLI, 2012).

Mesmo nos destinos que ainda não alcançaram um status de governança ou gestão integrada do setor, é comum atividades em redes empresariais conduzidas pelas associações, sindicatos e instituições do turismo (TUOHINO; KONU, 2014), ou seja, é usual a formação de networks dentro do destino. Van der Zee e Vanneste (2015) consideram que dentro do destino turístico a coopetição é o comportamento-base, e que a formação de uma rede turística ajuda a equilibrar a competição e a colaboração para incrementar o rendimento, tanto do destino como dos stakeholders.

A coopetição pode ocorrer de forma intencional ou não intencional. Neste último caso, considera-se como top-down, ou seja, gerada por força de mercado ou estratégias políticas (KYLÄNEN; RUSKO, 2011). No entanto, a consciente e desejada participação em relações de coopetição gera um sistema coopetitivo botton-up. Essa forma pode ser identificada no destino turístico pela participação ativa e voluntária dos stakeholders nas redes associativas, no associacionismo.

Os fatores de sucesso para um sistema de coopetição identificados por Chin et al. (2008) apoiam esses pressupostos, pois identificaram variáveis que indicam a participação consciente, como, por exemplo, acordos de longo prazo e intercâmbio de informações. Outros autores também apontam que uma rede de coopetição forte necessita fundamentar-se em projetos e metas comuns, empresários ativos e uma gestão eficaz, itens que indicam a intencionalidade e o associacionismo (DELLA LUCIA et al., 2007; DELLA CORTE, 2009).

O grau de consciência dos atores sobre as vantagens geradas pela formação de redes associativas é de extrema importância para a coopetição, pois os estudos de Partnering indicam que o associacionismo, quando bem conduzido, se eleva a uma categoria de recursos, gerando vantagens competitivas superiores (KRIPPAEHNE et al., 1992; CHENG et al., 2000; EISENHARDT; MARTIN, 2000; DELLA CORTE; ARIA, 2014, 2016). Nesse sentido, quanto maior a consciência dos empresários sobre essas vantagens, melhor será sua propensão a participar de redes colaborativas para desenvolvimento de um destino turístico. 


\section{Metodologia}

O método de estudo de caso tem sido amplamente utilizado nas pesquisas em ciências sociais e especialmente no turismo (KYLÄNEN; RUSKO, 2011). Para o objetivo deste trabalho, esta metodologia permite estudar um fenômeno contemporâneo no seu contexto real, utilizando diversas fontes de evidência, assim como indica Yin (1994). É uma metodologia ideal para descrever e explorar uma teoria compreendida a partir das interações de diversas partes de um sistema (CHIVA-GÓMEZ, 2001), possibilitando a ampliação e generalização não estatística, mas uma generalização analítica, tal como previsto por Bonache-Pérez (1999).

Considerando o anteriormente exposto, e com base na revisão da literatura, propõem-se oito variáveis que indicam o contexto empresarial turístico relacionado ao associacionismo e à coopetição no destino turístico (Figura 1). Trata-se de uma compilação e síntese de variáveis que coincidem nos marcos teóricos de associacionismo (partnering), redes interorganizacionais e coopetição fazendo uma adaptação a destinos turísticos. Assim, por um lado, a partir da existência de um nível de confiança que a rede turística irá gerar vantagens individuais, bem como coletivas, é que se gera o engajamento, apoio e participação das organizações, que resulta em associativismo (KRIPPAEHNE et al., 1992; CHENG et al., 2000; EISENHARDT; MARTIN, 2000; DELLA CORTE; ARIA, 2014, 2016; CHIM-MIKI; BATISTACANINO, 2017). Por sua vez, a associação forma as redes interorganizacionais cujo comportamento no destino turístico é baseado em coopetição (DELLA CORTE; SCIARELLI, 2012; KYLÄNEN; RUSKO, 2011; VAN DER ZEE; ZANNESTE, 2015).

\section{Figura 1 - Contexto crítico de Associacionismo e Coopetição no destino turístico}

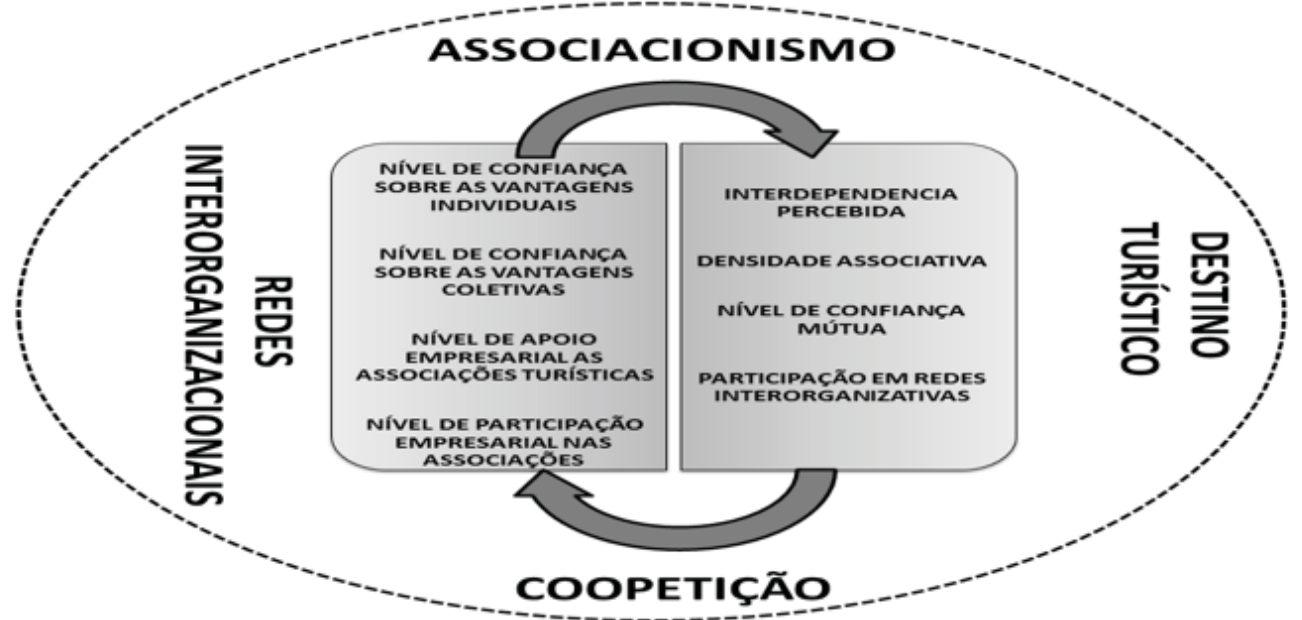

Fonte: Elaboração própria

Dessa forma, para cada variável a ser verificada, buscou-se na literatura escalas de medida validadas anteriormente por outras pesquisas empíricas em ambientes interorganizacionais, ou seja, questões utilizadas para medir o construto-base, e providenciou-se uma adaptação das questões ao contexto de destino turístico que pode ser observada na seção de instrumentos de coleta de dados. 
Salienta-se que os sindicatos empresariais foram incluídos como associação, porém, consideraram-se somente os seus sócios efetivos e não todo o grupo de empresas representadas pela categoria, ou seja, somente os associados ativos. As normas brasileiras preveem a afiliação sindical em função do Código Nacional de Atividade Empresarial (Cnae), no entanto, existe uma diferença entre participar da categoria por força de um dispositivo legal e ser efetivamente sócio do sindicato. Também consideraram como associação turística as câmaras e comitês públicos do turismo que congregam redes interorganizacionais para seu funcionamento, planejamento ou gestão do setor, como, por exemplo, o Conselho Municipal de Turismo (Comtur).

\section{Contexto de análise}

Duas cidades que são importantes destinos turísticos localizadas no sul do Brasil foram analisadas. A cidade de Curitiba, capital do estado do Paraná, e a maior do sul do país, que ocupa a $5^{\text {a }}$ posição no ranking nacional de competitividade entre os 65 destinos indutores de turismo, é classificada como um destino urbano e recebeu, em 2012, um total de 3.653.300 turistas. As motivações de viagens para esse destino turístico são principalmente por negócios (35,8\% do fluxo turístico), seguido de visitas a amigos $(27,1 \%)$, por lazer (18,5\%), outros motivos são por saúde (7,5\%), estudos, eventos e compras $(3,9 \%)$. O turista apresenta um gasto diário no destino de US\$70,2, com média de permanência de 4,4 dias (SECRETARIA DE TURISMO DO ESTADO DO PARANÁ - SETU, 2012).

A outra cidade pesquisada também se situa no estado do Paraná. Foz do Iguaçu representa um destino compartilhado entre três cidades da tríplice fronteira entre Brasil-Paraguai-Argentina. É um destino de natureza, cuja principal motivação de visita é por lazer (58,6\% do fluxo turístico), seguido de turismo de negócios (14,2\%), visita a familiares e amigos (13,7\%) e eventos (3,1\%). O gasto médio diário no destino é de US\$ 98,6 e a média de permanência é de 3,6 dias (SECRETARIA DE TURISMO DO ESTADO DO PARANÁ - SETU, 2012). No ranking nacional, ocupa a 6 $6^{\text {a }}$ posição em competitividade turística entre os 65 destinos indutores monitorados pelo Ministério do Turismo.

\section{Amostragem e fontes de informação}

Para melhorar a validez do modelo e a objetividade do tratamento da informação, utilizaram-se diversas fontes de informação, garantindo a validez interna e a confiabilidade do estudo (PETTIGREW, 1990; YIN, 1994). Concretamente, este estudo considerou como informantes-chaves os empresários do setor turístico, os diretores de associações ou organizações do setor nas duas cidades analisadas e representantes do setor público relacionado ao turismo.

Para a amostragem de organizações turísticas, utilizou-se a técnica bola de neve, atingindo três níveis de indicações. Primeiro, foram entrevistadas as organizações turísticas que participavam do Comtur de cada cidade. Em um segundo estágio, foram entrevistadas as associações indicadas pelos primeiros entrevistados como sendo atuantes para o desenvolvimento turístico do destino ainda que não participantes do Comtur. E no último estágio foram entrevistadas redes empresariais indicadas pelos segundos entrevistados. $\mathrm{O}$ processo dessa metodologia de amostragem e os critérios definidos podem ser observados na Figura 2, o qual resultou em 24 associações/organizações entrevistadas em Curitiba, e 26 em Foz do Iguaçu. 
Figura 2 - Processo de amostragem das associações turísticas

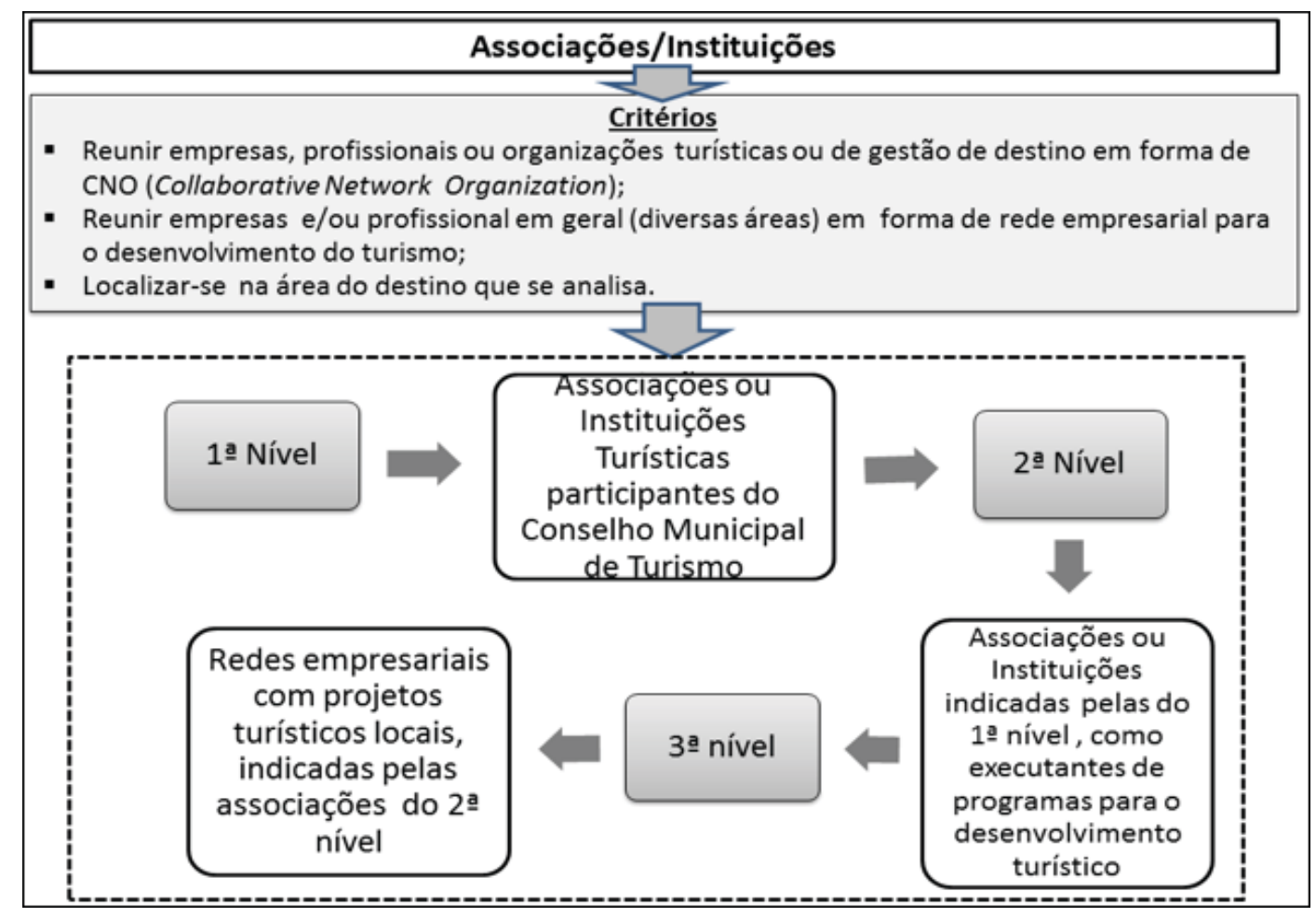

Fonte: Elaboração própria

Por outro lado, a amostragem de empresas turísticas foi não probabilística e estratificada segundo os percentuais de participação de atividade empresarial no universo total de empresa turística agrupada por Código Nacional de Atividades Empresariais - Cnae (Tabela 1).

Tabela 1 - Composição da amostra definitiva comparativamente ao universo ${ }^{1}$ de cada cidade

\begin{tabular}{|c|c|c|c|c|c|c|c|c|c|c|}
\hline \multirow{2}{*}{$\begin{array}{l}\text { Atividade } \\
\text { empresarial }\end{array}$} & \multicolumn{5}{|c|}{ CURITIBA } & \multicolumn{5}{|c|}{ FOZ DO IGUAÇU } \\
\hline & Universo & $\%$ & $\begin{array}{l}\text { Amostra } \\
\text { estimada }\end{array}$ & $\begin{array}{l}\text { Amostra } \\
\text { real }\end{array}$ & $\%$ & Universo & $\%$ & $\begin{array}{l}\text { Amostra } \\
\text { estimada }\end{array}$ & $\begin{array}{c}\text { Amostra } \\
\text { real }\end{array}$ & $\%$ \\
\hline 1. Hospedagem & 283 & 11,3 & 38 & 47 & 16,3 & 176 & 26,2 & 64 & 85 & 33,0 \\
\hline 2. Restauração & 1.130 & 45,0 & 150 & 108 & 37,7 & 206 & 30,7 & 75 & 69 & 26,7 \\
\hline 3. Agências & 380 & 15,1 & 51 & 51 & 17,8 & 131 & 19,5 & 48 & 43 & 16,7 \\
\hline 4. Transportes & 232 & 9,2 & 31 & 30 & 10,4 & 48 & 7,2 & 18 & 22 & 8,5 \\
\hline $\begin{array}{l}\text { 5. Empresas de lazer e } \\
\text { complementos }\end{array}$ & 488 & 19,4 & 65 & 51 & 17,8 & 110 & 16,4 & 40 & 39 & 15,1 \\
\hline Total & 2.513 & 100 & 334 & 287 & 100 & 671 & 100,0 & 245 & 258 & 100 \\
\hline
\end{tabular}

1Informação baseada no Inventário da Oferta Turística de Foz do Iguaçu (2014), Plano de Desenvolvimento Integrado do Turismo Sustentável - PDITS (2013), relatórios de Ipards e Rais ano-base 2013.

Fonte: Elaboração própria 
A cidade de Curitiba possuía 2.513 empresas turísticas divididas entre 5 grupos de atividades. A partir desse universo determinou-se uma amostra estimada de 334 empresas (Tabela 1), porém, a amostra real obtida foi de 287 empresas, representando um erro amostral de 5,4\%. Referente a Foz do Iguaçu, a amostra atingiu 257 empresas sendo um erro amostral de 4,8\%. Nessa cidade, partiu-se de um universo de 671 empresas e, a princípio, pretendia-se uma mostra estimada de 245 empresas. O cálculo dessas amostras considerou a estimação com base em proporções de populações finitas, sendo $p$ e $q$ iguais a $50 \%$, com coeficiente de confiabilidade de 95\%. A Tabela 1 detalha a amostragem por grupo de atividade empresarial, e os dados de universo foram considerados a partir das informações da Relação Anual de Informações Sociais (Rais), Plano de Desenvolvimento Integrado do Turismo Sustentável - PDITS (2013) e relatórios do Instituto Paranaense de Desenvolvimento Econômico e Social (Ipards) para a cidade de Curitiba, e a partir das informações do Inventário Turístico Municipal para o caso de Foz do Iguaçu.

\section{Instrumentos de obtenção de dados}

Um estudo de caso permite uso de dados tanto qualitativos como quantitativos, mas mantendo o caráter qualitativo da metodologia global (CHIVA-GÓMEZ, 2001). Assim, nesta pesquisa utilizamos dois tipos de questionários. Um de percepção empresarial que verifica 16 questões em escala de 7 pontos, onde 1 representa a menor medida e 7 a maior. Esse questionário foi aplicado às empresas turísticas, e as questões são apresentadas no Quadro 1. Outro questionário foi aplicado a associações turísticas, contendo uma mescla de perguntas abertas, fechadas e uma questão de percepção em escala Likert.

\section{Quadro 1 - Escalas de medida do contexto crítico de Associacionismo e Coopetição no destino turístico}

\begin{tabular}{|c|c|}
\hline Variável & Escala/Questão \\
\hline $\begin{array}{l}\text { NÍVEL DE CONFIANÇA } \\
\text { SOBRE AS VANTAGENS } \\
\text { INDIVIDUAIS }\end{array}$ & $\begin{array}{l}\text { (Q1) Confio em que as decisões dos membros da associação de empresas e organizações turísticas } \\
\text { desse destino serão boas para meu negócio } \\
\text { (Q2) É importante manter uma relação de associação (pública ou privada) entre as empresas e } \\
\text { organizações turísticas do destino em que atuo em longo prazo }\end{array}$ \\
\hline $\begin{array}{l}\text { NÍVEL DE CONFIANÇA } \\
\text { SOBRE AS VANTAGENS } \\
\text { COLETIVAS }\end{array}$ & $\begin{array}{l}\text { (Q3) Confio em que as decisões dos membros da associação de empresas e organizações turísticas } \\
\text { desse destino serão boas para o desenvolvimento do destino } \\
\text { (Q4) Considero que a formação de associações ou redes cooperativas entre empresas turísticas é um } \\
\text { assunto estratégico para esse destino }\end{array}$ \\
\hline $\begin{array}{l}\text { NÍVEL DE APOIO } \\
\text { EMPRESARIAL ÀS } \\
\text { ASSOCIAÇÕES } \\
\text { TURÍSTICAS }\end{array}$ & $\begin{array}{l}\text { (Q5) A empresa designou um alto executivo para representá-la nas decisões da associação ou da rede } \\
\text { de cooperação } \\
\text { (Q6) Minha empresa tem mostrado um apoio ativo na formação de associações para o setor } \\
\text { facilitando recursos para seu desenvolvimento (dinheiro, tempo, mão de obra, e tomada de decisões) }\end{array}$ \\
\hline $\begin{array}{l}\text { NÍVEL DE PARTICIPAÇÃO } \\
\text { EMPRESARIAL NAS } \\
\text { ASSOCIAÇÕES }\end{array}$ & $\begin{array}{l}\text { (Q7) Participo da formulação de metas da associação ou governança desse destino } \\
\text { (Q8) Considero que uma associação de empresas turísticas do destino em que atuo é um recurso que } \\
\text { nos ajudará a posicionar melhor esse destino em longo prazo }\end{array}$ \\
\hline $\begin{array}{l}\text { INTERDEPENDÊNCIA } \\
\text { PERCEBIDA }\end{array}$ & $\begin{array}{l}\text { (Q9) A variedade de atividades turísticas é essencial para complementar a oferta desse destino } \\
\text { (Q10) Se deixar de existir cooperação entre empresas do setor, diminuirá a atratividade desse } \\
\text { destino }\end{array}$ \\
\hline $\begin{array}{l}\text { DENSIDADE } \\
\text { ASSOCIATIVA }\end{array}$ & $\begin{array}{l}\text { (Q11) É importante, para minha empresa, participar de uma rede de cooperação ou associação de } \\
\text { empresas ou organizações turísticas desse destino } \\
\text { (Q12) Tenho intenção de manter relações de cooperação com empresas do setor }\end{array}$ \\
\hline $\begin{array}{l}\text { NÍVEL DE CONFIANÇA } \\
\text { MÚTUA }\end{array}$ & $\begin{array}{l}\text { (Q13) Podemos confiar nas outras empresas e organizações turísticas desse destino para formar uma } \\
\text { aliança estratégica } \\
\text { (Q14) Em minha opinião, existe um objetivo comum e compartilhado entre as empresas turísticas } \\
\text { desse destino }\end{array}$ \\
\hline $\begin{array}{l}\text { PARTICIPAÇÃO } \\
\text { EM REDES } \\
\text { INTERORGANIZATIVAS }\end{array}$ & $\begin{array}{l}\text { (Q15) Ajudo a uma associação ou governança desse destino em seu planejamento de atividades } \\
\text { (Q16) Participo de redes ou projetos de cooperação empresarial não relacionada com o setor } \\
\text { turístico, cujo objetivo é promover a cidade ou região em que atuo }\end{array}$ \\
\hline
\end{tabular}

Fonte: Elaboração própria 
Em uma primeira fase, os questionários foram enviados por e-mail, mas, devido ao baixo índice de respostas, realizou-se uma segunda fase, em que os questionários foram aplicados pessoalmente por uma equipe de pesquisadores. As duas fases do trabalho de campo ocorreram nos meses de julho a novembro de 2015 .

\section{Resultados}

Entre as principais características das associações turísticas que participaram da amostragem se destaca que em ambas as cidades aproximadamente $80 \%$ são associações privadas, com pagamento de taxa mensal. (Tabela 2). Em segundo lugar, observa-se na Tabela 2 a existência de associações de natureza obrigatória e gratuita (12,5\% em Curitiba e 15,4\% em Foz do Iguaçu). Esses resultados indicam que o associacionismo em ambas as cidades é um fenômeno privado muito mais que fomentado pela ação pública no setor do turismo.

Tabela 2 - Características das associações turísticas quanto a sua natureza

\begin{tabular}{|c|c|c|c|c|}
\hline \multirow{2}{*}{ Característica } & \multicolumn{2}{|c|}{ CURITIBA } & \multicolumn{2}{|c|}{ FOZ DO IGUAÇU } \\
\hline & Frequência & $\%$ & Frequência & $\%$ \\
\hline \multicolumn{5}{|l|}{ Natureza da Associação } \\
\hline Obrigatória e gratuita & 3 & 12,5 & 4 & 15,4 \\
\hline Obrigatória e taxa de associação & 0 & 0 & 0 & 0 \\
\hline Optativa e gratuita & 1 & 4,2 & 2 & 7,7 \\
\hline Optativa e com taxa de associação & 20 & 83,3 & 20 & 76,9 \\
\hline Total & 24 & 100 & 26 & 100 \\
\hline \multicolumn{5}{|l|}{ Caráter da Associação } \\
\hline Organismo Governamental (Instituição pública) & 4 & 16,7 & 3 & 11,5 \\
\hline $\begin{array}{l}\text { Organismo de iniciativa privada (Instituição } \\
\text { privada) }\end{array}$ & 19 & 79,2 & 21 & 80,8 \\
\hline Organismo Misto (público-privado) & 1 & 4,2 & 2 & 7,7 \\
\hline Total & 24 & 100 & 26 & 100 \\
\hline
\end{tabular}

Fonte: Elaboração própria

Por outro lado, com relação à área de cobertura geográfica das associações, visualizam-se diferenças. Curitiba possui um equilíbrio entre associações que incluem sócios locais, regionais e nacionais. Vinte por cento $(20 \%)$ das associações entrevistadas nesse destino turístico são integradas por empresas de bairros ou áreas específicas da cidade. Um exemplo é a Associação de Comerciantes da Plaza de Espanha (Ascores). Já Foz do Iguaçu concentra mais associações compostas por sócios localizados na cidade (57\% das associações), não tendo sido encontrado caso de associações de determinadas áreas da cidade (Tabela 3). No entanto, em Foz do Iguaçu prevalecem sócios de setores de atividades específicas. Assim, esses números indicam que Foz do Iguaçu estabelece mais redes horizontais que Curitiba, portanto, indicam maior propensão à coopetição vertical e integral. 
Tabela 3 - Características das associações turísticas quanto à área territorial de cobertura e perfil de associados

\begin{tabular}{|c|c|c|c|c|}
\hline \multirow{2}{*}{ Característica } & \multicolumn{2}{|c|}{ CURITIBA } & \multicolumn{2}{|c|}{ FOZ DO IGUAÇU } \\
\hline & Frequência & $\%$ & Frequência & $\%$ \\
\hline \multicolumn{5}{|l|}{ Área territorial de cobertura } \\
\hline $\begin{array}{l}\text { Os associados devem ter sede localizada em um } \\
\text { bairro ou área específica da cidade }\end{array}$ & 5 & 20,8 & 0 & 0 \\
\hline $\begin{array}{l}\text { Os associados devem ter sede localizada na área } \\
\text { do município }\end{array}$ & 4 & 16,7 & 15 & 57,7 \\
\hline $\begin{array}{l}\text { Os associados devem ter sede localizada na área } \\
\text { regional da cidade }\end{array}$ & 4 & 16,7 & 8 & 30,8 \\
\hline $\begin{array}{l}\text { Os associados devem ter sede localizada no } \\
\text { estado }\end{array}$ & 6 & 25,0 & 1 & 3,8 \\
\hline Os associados devem ter sede localizada no país & 5 & 20,8 & 2 & 7,7 \\
\hline Total & 24 & 100 & 26 & 100 \\
\hline \multicolumn{5}{|l|}{ Perfil dos associados } \\
\hline Empresas em geral & 7 & 21,9 & 3 & 8,6 \\
\hline $\begin{array}{l}\text { Somente empresas ou organismos relacionados } \\
\text { com a atividade turística }\end{array}$ & 7 & 21,9 & 9 & 25,7 \\
\hline $\begin{array}{l}\text { Somente empresas ou organismos relacionados } \\
\text { com um tipo específico de atividade empresarial }\end{array}$ & 9 & 28,1 & 17 & 48,6 \\
\hline Organismos governamentais & 3 & 9,4 & 0 & 0 \\
\hline Organização sem fins lucrativos & 2 & 6,3 & 1 & 2,9 \\
\hline $\begin{array}{l}\text { Qualquer pessoa ou organização interessada no } \\
\text { desenvolvimento turístico do destino }\end{array}$ & 1 & 3,1 & 0 & 0 \\
\hline Somente pessoas físicas (não empresas) & 3 & 9,4 & 5 & 14,3 \\
\hline Total & 24 & 100 & 26 & 100 \\
\hline
\end{tabular}

Fonte: Elaboração própria

Quanto à percepção empresarial do ambiente associativo e coopetitivo no setor turístico, no geral, observou-se que Foz do Iguaçu possui mais acentuada a consciência sobre as vantagens derivadas do associativismo, consequentemente, são empresas com comportamento mais propenso à coopetição.

A Figura 3 apresenta o resultado do ambiente de associacionismo. As variáveis Q1 e Q2 tiveram a mesma pontuação nas duas cidades indicando que os empresários têm um nível de confiança média no quesito, ou seja, eles consideram que as decisões das associações serão boas para o seu negócio (Q1), e que é importante manter redes associativas público-privadas no destino (Q2). Com relação às vantagens coletivas, os números indicam que em Curitiba existe menos confiança que as decisões da associação serão boas para o destino (Q3), mas os entrevistados entendem que o associacionismo é uma questão estratégica (Q4). Por outro lado, em ambas as cidades os empresários percebem que dão pouco suporte às associações, tanto em termos de representatividade (Q5) como de apoio material (Q6). Igualmente, o baixo apoio está refletido na percepção empresarial quanto ao nível de participação efetiva no planejamento das ações da associação, a qual apresentou níveis bem baixos em Curitiba, e em Foz do Iguaçu também não atingiu a 
escala média (Q7). Contradizendo sua própria ação, os entrevistados apresentam uma percepção geral de que o associacionismo pode ser um recurso que gera capacidade competitiva (Q8), tendo apresentado uma consciência maior sobre esse fato em Foz do Iguaçu (Figura 3).

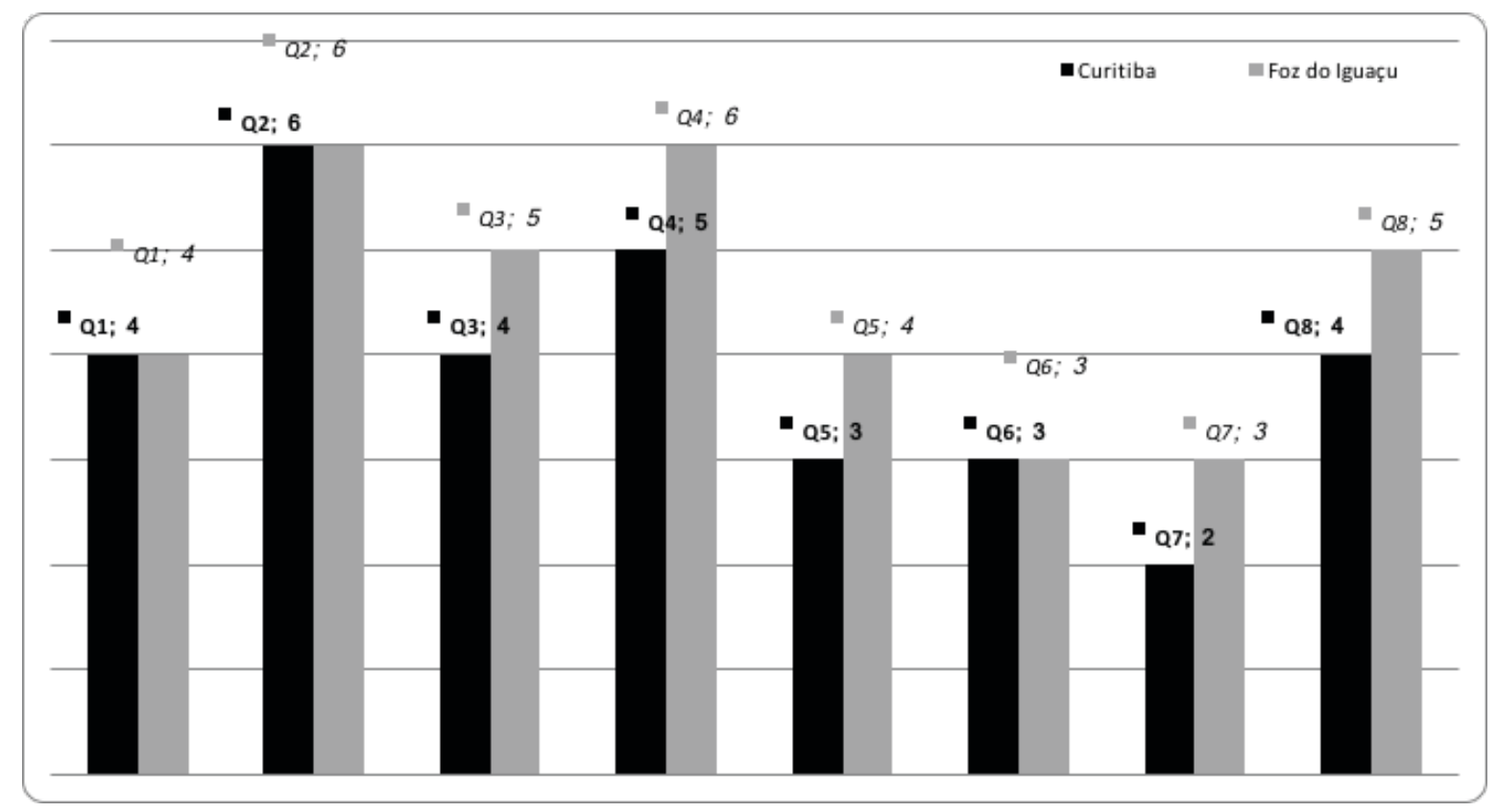

Figura 3 - Comparação da percepção empresarial do contexto associativista

Fonte: Elaboração própria

Na Figura 4 pode ser observado o resultado do contexto de coopetição em ambas as cidades. Verifica-se que, por outro lado, existe uma alta percepção empresarial relativa à interdependência e complementariedade entre as empresas turísticas em ambas as cidades, ainda que Foz do Iguaçu apresenta ligeira vantagem (Q9 e Q10). Exatamente a mesma pontuação reflete a percepção dos entrevistados de Curitiba e de Foz do Iguaçu, com relação a sua intenção em participar de redes empresariais de colaboração com outras empresas, assim como relativo à importância disso para sua empresa (Q11 e Q12). Enquanto que a confiança mútua é mais baixa na cidade de Curitiba entre os empresários (Q13), e a percepção de que compartilham uma meta comum de desenvolver o destino turístico também é baixa (Q14). Em Foz do Iguaçu demonstram melhores índices, tanto de confiança mútua quanto de consciência dos objetivos em comum.

Por último, novamente observou-se um baixo nível de percepção dos empresários sobre sua efetiva participação na governança do setor (Q15). Igualmente, baixo grau de participação destes em outras redes de cooperação de diferentes setores, mas que impactam no desenvolvimento da cidade como um todo (Q16). 


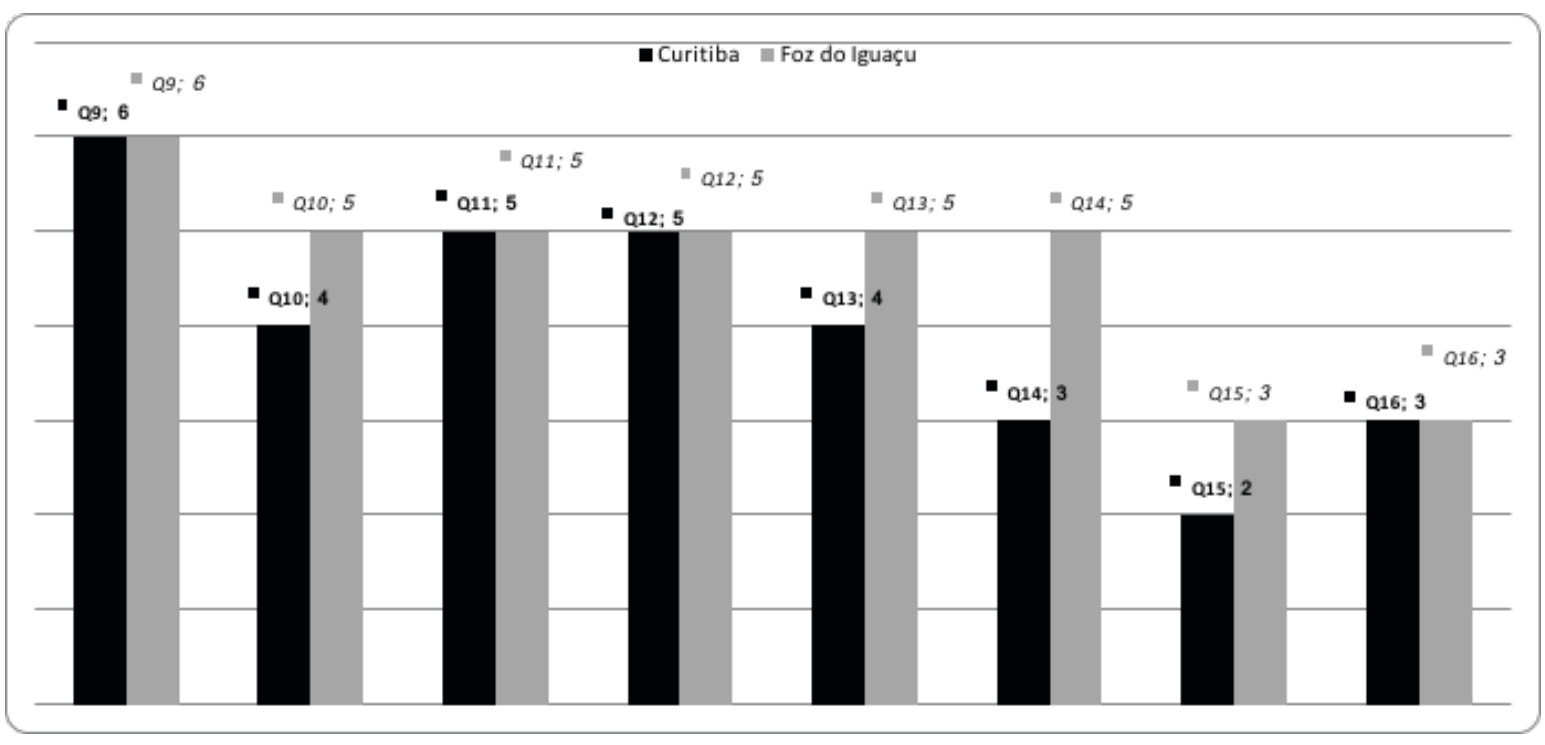

Figura 4 - Comparação da percepção empresarial do contexto Coopetição

Fonte: Elaboração própria

No geral, Foz do Iguaçu apresentou melhores indicativos da formação de coopetição turística do que Curitiba (Figura 4). Essa diferença foi gerada, principalmente, pela maior confiança mútua empresarial e visão de objetivos compartilhados.

De forma geral, os resultados observados nas figuras 3 e 4 confirmam os pressupostos teóricos anteriormente comprovados por outros autores, tanto dentro da área do turismo como de diferentes atividades. A interdependência e complementariedade na rede tornam-se chaves para a gestão mediante coopetição, assim como a consciência sobre as vantagens e a confiança mútua.

\section{Conclusões e considerações finais}

As relações entre empresas e organizações que se traduzem em um esforço conjunto para benefício mútuo não se limitam a alianças, acordos de coprodução ou comarketing, mas a todos os esforços coletivos e podem ser estudadas sob a perspectiva de coopetição (LUO, 2007). Coopetição é um comportamento frequente no turismo por meio das redes interorganizacionais que se formam para a gestão do destino, no entanto, o construto ainda é pouco estudado nesse setor. Este trabalho objetivou verificar o associacionismo turístico na cidade de Curitiba e Foz do Iguaçu, pois as associações podem ser consideradas vetores da coopetição, assim como demonstram um grau de intencionalidade na rede empresarial em participar de redes coopetitivas.

Foi verificada a percepção empresarial sobre 16 questões que, segundo a literatura, representam contextos críticos para o associacionismo e para a coopetição no setor turístico. Em suma, realizou-se uma análise do contexto operativo das associações turísticas dessas cidades. O resultado desses cenários indicou que Foz do Iguaçu possui melhor capacidade de desenvolver redes de coopetição. Por um lado, observou-se que as associações formam redes locais e horizontais com mais frequência que Curitiba e, por 
outro lado, verificou-se que os empresários de Foz do Iguaçu percebem mais acentuadamente as vantagens do associacionismo, a existência de valores compartidos e de objetivos comuns.

Também, Foz do Iguaçu mantém melhor percepção sobre a interdependência e complementariedade entre as organizações do setor turístico para formar o produto integral "Destino Turístico", fatores que são primordiais para a formação de sistemas de coopetição em qualquer setor (DAGNINO; PADULA, 2007; DELLA CORTE; SCIARELLI, 2012). Deve-se salientar que a cidade de Curitiba possui uma vasta rede empresarial em número de empresas, porém, sendo uma grande cidade e capital, seu tecido empresarial tende a remodelar-se com mais frequência, diminuindo a força dos vínculos, enquanto que em Foz do Iguaçu, sendo uma cidade pequena, os vínculos relacionais se acentuam. Nessa cidade, observaram-se que os empresários participam de mais de uma associação e muitas vezes em cargos de diretoria, ou seja, existe a formação de uma network social e profissional, o que gera maior grau de confiança mútua e percepção das vantagens colaborativas.

Extrai-se do questionário de percepção empresarial que, nas duas cidades, os empresários indicam visualizar as vantagens da coopetição, tanto para suas empresas (nível individual) como para o destino e setor turístico (nível coletivo). No entanto, no questionário aplicado aos empresários, estes foram absolutamente sinceros quanto a sua própria participação, reconhecendo que existe baixo nível de apoio às associações, assim como que participam pouco do planejamento da associação e da governança do destino. Esse aspecto não foi motivo de pergunta no questionário realizado às associações, mas em todos os casos foi motivo de queixa. Quando o entrevistador explicava o motivo da pesquisa, a reação foi similar em todos os casos, havendo uma queixa generalizada por parte da direção das associações em relação à pouca atenção e apoio dos empresários às ações da associação.

Um fator que pode ser um propulsor do melhor resultado dos indicadores em Foz do Iguaçu é que nas associações prevalecem sócios de empresas localizadas na cidade e frequentemente dos mesmos subsetores de atividades, ou seja, formam redes de cooperação horizontal. Ainda que nesse caso a coopetição é baseada mais em concorrência do que cooperação, o compartilhamento de uma meta e de problemas em comum estreita os laços na rede interorganizacional. Enquanto que na cidade de Curitiba, também por ser uma capital, existem muitas associações regionais ou representantes nacionais, gerando uma dispersão da força local. Nesse caso, ocorre maior formação de redes verticais, e assim a coopetição é mais baseada em cooperação, o que descentraliza a formação de um objetivo comum.

Em termos teóricos, pode-se concluir que as redes de coopetição baseadas em concorrência tendem a ser mais efetivas. Essa perspectiva também foi identificada pela pesquisa realizada por Della Corte e Sciarelli (2012) em destinos turísticos italianos. Igualmente, pode-se inferir que o tamanho da rede é um fator influenciador da formação da confiança mútua que gera um melhor estabelecimento e visualização de objetivos comuns.

De fato, existe divergência e convergência entre o associacionismo e a coopetição. A formação de redes entre empresas concorrentes, complementárias e provedoras em prol de um objetivo comum representa o associacionismo baseado em coopetição. No entanto, a coopetição como estratégia deve ser intencional, proativa e gerar resultados conscientemente perseguidos, representando uma gestão botton-up (DELLA CORTE; SCIARELLI, 2012). Nesse ponto está a divergência entre o associacionismo e a coopetição, visto que a simples participação como associado em uma rede organizacional não significa dizer que seja coopetitivo, é preciso ser atuante. A coopetição deve resultar em benefícios individuais e coletivos, ou pelo menos coletivos, segundo os objetivos estabelecidos pela rede e pelos programas implantados. Esses 
resultados corroboram Bengtsson e Kock (2000) que sustentam o uso de um ator intermediário, como uma associação, gerenciar estrategicamente a coopetição, atenuando as tensões típicas desse comportamento e gerando relações mais sólidas.

Dessa forma, pode-se afirmar que as associações são vetores para que a coopetição ocorra, mas não são a coopetição em si mesmo. Isso responde ao questionamento teórico, se os construtos de Partnering (CHENG et al., 2000) e de Coopetição (BRANDENBURGER; NALEBUFF, 1996) são sinônimos? Dentro das associações ocorre coopetição em diversos graus e com diferentes grupos de empresas, podendo em alguns casos abranger todos os associados. A coopetição é vista nos programas conduzidos pelas associações como ações de comarketing, de desenvolvimento de recursos humanos, implantação de ações de desenvolvimento turístico e outros. Assim, existe uma inegável convergência entre esses conceitos, sendo um a base da existência do outro, visto que as associações são gerenciadas com base no comportamento de coopetição. Elas são um espaço e vetor para esse comportamento ganhar força e forma no destino turístico.

Este trabalho contribui para a formação de uma base teórica empírica do uso da perspectiva de coopetição no turismo. Essa perspectiva é crescente em outros setores econômicos e expressa adequadamente as relações empresariais atuais, bem como a forma organizativa dos destinos turísticos. Além disso, esta pesquisa deixa uma contribuição prática aos destinos turísticos de Curitiba e Foz do Iguaçu, pois ao serem radiografados pelos indicadores utilizados neste trabalho, podem ver refletidos seus pontos fortes e fracos para estabelecer uma estratégia de coopetição. Assim poderão realizar ajustes comportamentais para obter mais vantagens coopetitivas tanto em nível das empresas como do destino.

As limitações desta pesquisa se relacionam ao baixo número de destinos pesquisados. Portanto, sugerem-se pesquisas em outros destinos para propiciar uma comparação dos resultados a fim de tender a futuras generalizações estatísticas e não somente uma generalização analítica. Além disso, como agenda de pesquisa, indica-se a determinação de um modelo multidimensional que expresse a capacidade de coopetição, permitindo sua mensuração em destinos turísticos.

\section{Referências}

BENGTSSON, M.; KOCK, S. Coopetition in business Networks - to cooperate and compete simultaneously. Industrial Marketing Management, v. 29, n. 5, p. 411-426, 2000.

BONACHE PÉREZ, J. El estudio de casos como estrategia de construcción teórica: características, críticas y defensas. Cuadernos de Economía y Dirección de la Empresa, v. 3, p. 123-14, 1999.

BRANDENBURGER, A. M.; NALEBUFF, B. J. Co-opetition: a revolutionary mindset that combines competition and cooperation in the marketplace. Boston: Harvard Business School Press, 1996.

CHENG, E. W.; LI, H.; LOVE, P. E. D. Establishment of critical success factors for construction partnering. Journal of Management in Engineering, v. 16, n. 2, p. 84-92, 2000.

CHIM-MIKI, A. F. Desarrollando un modelo de Coopetición: una aplicación al sector turístico en Brasil. Tesis (Doctorado) - Programa de Doctorado en Turismo, Economía y Gestión. Facultad de Empresa y Turismo. Universidad de Las Palmas de Gran Canaria, España, 2016. 
CHIM-MIKI, A. F.; BATISTA-CANINO, R. M. La investigación sobre coopetición: estado actual del conocimiento y sus implicaciones en los estudios turísticos. Estudios y Perspectivas en Turismo, v. 25, n. 4, p. 399-415, 2016.

. The coopetition perspective applied to tourism destinations: a literature review. Anatolia, v. 28, n. 3, p. 381-393, 2017.

CHIN, K-S.; CHAN, B. L.; LAM, P-K. Identifying and prioritizing critical success factors for coopetition strategy. Industrial Management \& Data Systems, v. 108, n. 4, p. 437-454, 2008.

CHIVA GÓMEZ, R. El estudio de casos explicativo. Una reflexión. Revista de Economía y Empresa, v. 41, p. 119-132, 2001.

CROWLEY, L. G.; KARIM, M. A. Conceptual model of partnering. Journal of Management in Engineering, V. 11, n. 5 , p. 33-39, 1995.

DELLA CORTE, $V$. The light side and the dark side of inter-firm collaboration: how to govern distrust in business networks. Corporate Ownership and Control, v. 6, n. 4, p. 407-426, 2009.

DELLA CORTE, V.; SCIARELLI, M. Can coopetition be source of competitive advantage for strategic networks? Corporate Ownership and Control, v. 10, n. 1, p. 363-379, 2012.

DELLA CORTE, V.; ARIA, M. Why strategic networks often fail: some empirical evidence from the area of Naples. Tourism Management, v. 45, p. 3-15, 2014.

Coopetition and sustainable competitive advantage. The case of tourist destinations. Tourism Management, v. 54, p. 524-540, 2016.

DELLA LUCIA, M. et al. Metodologia della ricerca. SCIARELLI, S. (a Cura Di). Il Management dei Sistemi Turistici Locali: strategie e strumenti per la governanc. Torino: Giappichelli, 2007.

EISENHARDT, K. M.; MARTIN, J. A. Dynamic capabilities: What are they? Strategic Management Journal, V. 21, n. 10-11, p. 1105-1121, 2000.

FYALL, A.; GARROD, B.; WANG, Y. Destination collaboration: a critical review of theoretical approaches to a multi-dimensional phenomenon. Journal of Destination Marketing and Management, v. 1, n. 1, p. 10-26, 2012.

GARRAFFO, F. Types of coopetition to manage emerging technologies. In Proceedings of the II Annual Conference of Euramon: “Innovative Research Management". Track: "Coopetition Strategy: Towards a New Kind of Interfirm Dynamics” (p. 9-11). Stockholm, 2002.

HARBACK, H. F.; BASHAM, D. L.; BUHTS, R. E. Partnering paradigm. Journal of Management in Engineering, v. 10, n. 1, p. 23-27, 1994.

KRIPPAEHNE, R. C.; MCCULLOUCH, B. G.; VANEGAS, J. A. Vertical business integration strategies for construction. Journal of Management in Engineering, v. 8, n. 2, p. 153-166, 1992.

KYLÄNEN, M.; RUSKO, R. Unintentional coopetition in the service industries: the case of pyhä-luosto tourism destination in the Finnish Lapland. European Management Journal, v. 29, n. 3, p.193-205, 2011.

LUO, Y. Toward coopetition within a multinational enterprise: a perspective from foreign subsidiaries. Journal of World Business: JWB, v. 40, n. 1, p. 71-90, 2005.

. A coopetition perspective of global competition. Journal of World Business: JWB, v. 42, n. 2, p. $129-144,2007$. 
MOHR, J.; SPEKMAN, R. Characteristics of partnership success: partnership attributes, communication behavior, and conflict resolution techniques. Strategic Management Journal, v. 15, n. 2, p. 135-152, 1994 .

PADULA, G.; DAGNINO, G. Untangling the rise of coopetition: the intrusion of competition in a cooperative game structure. International Studies of Management \& Organization, v. 37, n. 2, p. 32$52,2007$.

PDITS CURITIBA. Plano de Desenvolvimento Sustentável de Curitiba. Curitiba: Secretaria de Turismo, Prefeitura Municipal de Curitiba, 2013.

PETTIGREW, A. Longitudinal field research on change: theory and practice. Organization Science, v. 1, p. 267-291, 1990.

RAIS. Relação Anual de Informações Sociais, 2013. Disponível em: 〈http://www.mtps.gov.br/dadosabertos〉.

SECRETARIA DE TURISMO DO ESTADO DO PARANÁ - SETU. Secretaria de Turismo do Estado do Paraná. Projeto de pesquisa de demanda turística 2012. Curitiba: Instituto Municipal Curitiba Turismo, 2012.

TUOHINO, A.; KONU, H. Local stakeholders' views about destination management: who are leading tourism development? Tourism Review, v. 69, n. 3, p. 202-215, 2014.

VAN DER ZEE, E.; VANNESTE, D. Tourism networks unravelled; a review of the literature on networks in tourism management studies. Tourism Management Perspectives, v. 15, p. 46-56, 2015.

WANG, Y. Collaborative destination marketing: roles and strategies of convention and visitors bureaus. Journal of Vacation Marketing, v. 14, n. 3, p. 191-209, 2008.

WANG, Y.; KRAKOVER, S. Destination marketing: competition, cooperation or coopetition? International Journal of Contemporary Hospitality Management, v. 20, n. 2, p. 126-141, 2008.

YIN, R. K. Case study research. Design and methods. Sage Publications, 1994. 